\title{
BMJ Open Socioeconomic inequality in functional deficiencies and chronic diseases among older Indian adults: a sex-stratified cross-sectional decomposition analysis
}

\author{
Lucky Singh, ${ }^{1}$ Richa Goel, ${ }^{2}$ Rajesh Kumar Rai, ${ }^{3}$ Prashant Kumar Singh ${ }^{4}$
}

To cite: Singh L, Goel R, Rai RK, et al. Socioeconomic inequality in functional deficiencies and chronic diseases among older Indian adults: a sex-stratified cross-sectional decomposition analysis. BMJ Open 2019;9:e022787. doi:10.1136/ bmjopen-2018-022787

- Prepublication history for this paper is available online. To view these files, please visit the journal online (http://dx.doi. org/10.1136/bmjopen-2018022787).

Received 8 March 2018 Revised 10 January 2019 Accepted 31 January 2019

\section{Check for updates}

(C) Author(s) (or their employer(s)) 2019. Re-use permitted under CC BY-NC. No commercial re-use. See rights and permissions. Published by BMJ.

${ }^{1}$ ICMR - National Institute of Medical Statistics, New Delhi, India

${ }^{2}$ Indian Council of Medical Research, New Delhi, India ${ }^{3}$ Society for Health and Demographic Surveillance, Suri, India

${ }^{4}$ Division of Preventive Oncology, ICMR - National Institute of Cancer Prevention and Research, Noida, Uttar Pradesh, India

Correspondence to

Dr Lucky Singh;

lucky.5bhu@gmail.com

\section{ABSTRACT}

Objectives Older adults with adverse socioeconomic conditions suffer disproportionately from a poor quality of life. Stratified by sex, income-related inequalities have been decomposed for functional deficiencies and chronic diseases among older adults, and the degree to which social and demographic factors contribute to these inequalities was identified in this study.

Design Cross-sectional study.

Participants Data used for this study were retrieved from the WHO Study on Global AGEing and Adult Health Wave 1. A total of 3753 individuals (men: 1979, and women: 1774) aged $\geq 60$ years were found eligible for the analysis

Measures Instrumental Activity of Daily Living (IADL) deficiency and presence of chronic diseases.

Method The decomposition method proposed by Adam Wagstaff and his colleagues was used. The method allows estimating how determinants of health contribute proportionally to inequality in a health variable.

Results Compared with men, women were disproportionately affected by both functional deficiencies and chronic diseases. The relative contribution of sociodemographic factors to IADL deficiency was highest among those with poor economic status (38.5\%), followed by those who were illiterate $(22.5 \%)$, which collated to $61 \%$ of the total explained inequalities. Similarly, for chronic diseases, about $93 \%$ of the relative contribution was shared by those with poor economic status (42.3\%), rural residence (30.5\%) and illiteracy (20.3\%). Significant difference in predictors was evident between men and women in IADL deficiency and chronic illness.

Conclusion Pro-poor intervention strategies could be designed to address functional deficiencies and chronic diseases, with special attention to women.

\section{INTRODUCTION}

Globally, older women experience lower mortality rates and in a few cases, lower prevalence of chronic diseases as compared with their male counterparts. ${ }^{1-4}$ Contrary to this, functional limitation and physical disability among women has been higher than that among men, particularly in low/middle-income countries. ${ }^{56}$ Existing evidence shows that the difference in male-female functional
Strengths and limitations of this study

- This study, the first of its kind, examines the decomposition of socioeconomic inequality in functional deficiency and chronic illness separately for older men and women.

- The findings revealed pro-poor inequality in Instrumental Activity of Daily Living (IADL) deficiency and pro-rich inequality in the occurrence of chronic diseases among both older men and women in India.

- While being poor and illiterate contributed highest to the IADL deficiency among men, rural residence followed by social group and religion contributed most among women.

- Being poor, lives in rural areas and illiterate contributed significantly to the chronic illness among men, whereas among women, it was poor economic status, rural residence and illiteracy.

- The cross-sectional study design prevents establishment of any causal inferences from the study results.

limitation could be explained in terms of higher prevalence and severity of arthritis and musculoskeletal disease ${ }^{47}$ among women along with psychosocial factors-women are more likely to over-report ill health and functional limitations, whereas men would under-report their weaknesses. ${ }^{8}$ This pattern may be more evident in low/middle-income countries where gender norms significantly determine demographic, health and socioeconomic outcomes.

Examining disparities in socioeconomic status and their effect on health outcomes in developing societies is high on the list of priorities in the global agenda. A study has shown that poor economic status contributes to over half of the inequality in self-rated health among older adults in India, followed by illiteracy and rural residence. ${ }^{9}$ However, the distribution of socioeconomic resources between men and women is not the same, which gives rise to different explanations 
for the existing socioeconomic inequalities in health by gender. Of the total older adult population in India, nearly half of them, mostly women, are dependants, often due to widowhood, divorce or separation. ${ }^{10}$ Majority of older adult women are deprived of economic security and receive poor healthcare. ${ }^{10}$ If results for male and female participants are not studied separately, aggregate results may mask imperative disparities in the mechanism of functional deficiency and chronic diseases. ${ }^{11}$

Stratified by sex, income-related inequalities for functional deficiencies and chronic diseases among older adults are decomposed, and the degree to which social and demographic determinants contribute to these inequalities is identified.

This study has the following objectives:

1. To examine the differences in functional deficiency and chronic diseases among older men and women separately

2. To estimate the relative contribution of socioeconomic and demographic factors to the overall functional deficiencies and chronic diseases, separately among men and women.

This study hopes to collate and analyse data to prepare and design programmes to improve the functional capacity and management of chronic diseases among the older adults in India. The National Health Policy of India, 2017 acknowledges the healthcare needs of the ageing population in India and recommends focused interventions ${ }^{12}$ to tackle the rising burden of functional deficiency and chronic diseases. ${ }^{13}$

\section{METHODS}

\section{Study population}

Data required for this study were retrieved from the WHO Study on Global AGEing and Adult Health (SAGE) Wave 1, collected between 2007 and 2010 in India. SAGE is a nationally representative multicountry (China, Ghana, India, Mexico, Russian Federation and South Africa) study to monitor the health and well-being of adult population aged 50 years and older. ${ }^{14}$ In India, respondents were selected from six states-Assam, Karnataka, Maharashtra, Rajasthan, Uttar Pradesh and West Bengal using a multistage, stratified, random sampling design with every individual having a known non-zero probability of being selected. Overall, the individual response rate was over 92\%. More about the sampling process and SAGE India survey can be obtained from the official report. ${ }^{14} 15$ This study followed the United Nation's agreed cut-off age for defining older population (60 years and older). A total of 3753 individuals (men: 1979, and women: 1774) aged 60 years and older were included in this study.

\section{Functional deficiency and chronic disease}

Two health outcome events, functional deficiency and presence of chronic diseases, were analysed. Functional deficiency was measured in terms of Instrumental Activity of Daily Living (IADL). IADL measures the ability to perform relatively complex activities of daily living. ${ }^{16}$ Studies have identified a hierarchical structure within the disablement process model from health to disability, and concluded that the first level of disability includes persons with only mobility impairment. ${ }^{17}$ The next level in the progression includes those with impairment in mobility plus a limitation in an IADL. Finally, level 3 includes those with mobility, IADL and basic difficulties in daily activities. ${ }^{17} 18$ Although, IADL may not assess functional limitation in basic tasks such as sitting or standing for a long period, bathing, dressing and so on, it provides a basic understanding of the onset of functional difficulties among older adults. ${ }^{19}$ This study follows the WHO-SAGE definition of IADL. In the WHO-SAGE survey, IADL is composed of five items that cover higher-level instrumental tasks. ${ }^{15}$ The respondents were asked if they had any difficulty doing the following instrumental tasks during the 30 days preceding the survey:

1. ...in taking care of your household responsibilities?

2. ...in joining community activities (eg, festivities, religious or other activities) in the same way as anyone else can?

3. ....in your day-to-day work?

4. ...in reaching your destination, using private or public transport if needed?

5 . ...in getting out of your home?

The responses were categorised into 'none', 'mild', 'moderate', 'severe' and 'extreme'/ 'cannot do'. For this study, the responses were grouped into different difficulty levels:

- No difficulty (when the response was none or mild or moderate $=0$ )

- Difficulty (when the response was severe or extreme $=1$ ).

The computed value of the sum of dichotomised five variables ranges from 0 to 5 , where the higher score indicates poor physical functioning.

Besides IADL, respondents were asked if they were diagnosed with any of the following chronic medical conditions (as conveyed by a healthcare professional): angina, asthma, stroke, depression, chronic lung disease and hypertension. An affirmative response regarding any of these medical conditions confirmed the presence of chronic disease.

\section{Covariates}

Guided by existing literature, individual and household level binary ( 1 or 0 ) covariates that could explain maximum dimensions of inequality were considered. The covariates are sex of the respondent (male or female), current marital status (married or unmarried), social group (Scheduled Caste/Scheduled Tribe or Non-scheduled Caste/Tribe), religion (Muslim or Others), education of the respondent (illiterate or literate), economic status (poor or non-poor), residence (rural or urban) and tobacco use (never, and ever or current). In dichotomous covariates, the assigned value ' 1 ' represents the older population in a disadvantaged socioeconomic group, and 
the assigned value of ' 0 ' indicates the older population in an advantageous position.

The critical role of marital status for a woman in Indian society has been documented in terms of lower access to material resources, and her own social position within and outside the family. ${ }^{20}$ Studies from India ${ }^{21}$ and elsewhere ${ }^{22}$ show that both objective and subjective health measures along with healthcare use are substantially lower among older widowed women than among their married counterparts. $^{23} 24$

Earlier literature suggests the protective effect of education on an individual's health, which operates in several ways. For instance, education may positively affect health through postponing the onset of functional limitations and chronic conditions, ${ }^{25}$ improve health through better management of illnesses and enhance individual capability to cope with negative emotions. ${ }^{26}$ Considering fewer resources, such as power, authority, earnings, household income and wealth among women, the role of education appears to be vital in explaining women's health in low/ middle-income countries like India. ${ }^{27}{ }^{28}$ Among lifestyle factors, physical inactivity, unhealthy diet, consumption of alcohol and use of tobacco have been found to be prominent risk factors for non-communicable diseases. ${ }^{29}{ }^{30} \mathrm{In}$ India, smoking is higher among men and they smoke throughout their lives. Women smoke less than men but tend to become smokers at an older age. ${ }^{31} 32$

Over $70 \%$ of the population lives in rural areas in India. Owing to variations in social experience, healthcare, pension policies, state provisions, rural and urban differences in health among older adults are critical. Moreover, with the increase of rural to urban migration among the young population for better education, employment and living opportunities, the older population left behind in rural areas is at risk. ${ }^{33}$

Historically, Scheduled Castes and Scheduled Tribes are identified by the Government of India as socially and economically backward social groups and considered to be in need of protection from social injustice and exploitation, whereas non-Scheduled Caste/Tribes enjoy a higher status in the social hierarchy. Economic groups (poor or non-poor) were derived from the household wealth index provided in the data set by using the WHO standard approach to estimate income from selected indicator variables. ${ }^{34}$ For the decomposition analysis, the top two quintiles (representing $40 \%$ of economic status) were grouped as non-poor, and the bottom three quintiles (representing $60 \%$ of economic status) were combined as poor.

\section{Analytical approach}

Stratified by sex, a decomposition analysis was conducted to measure the contribution of select covariates to explain the burden of IADL and presence of chronic diseases in following steps. ${ }^{35}$ First, to quantify the extent of socioeconomic inequality in IADL and chronic diseases outcomes, we used Concentration Index (CI).$^{36}$ It could be computed as twice the weighted covariance of health outcomes and relative ranking of individuals in economic gradient divided by variable mean as mentioned in equation (1). ${ }^{37}$ The range of CI varies between -1 and +1 , where a negative value refers that the poor health outcomes concentrated among the disadvantage group and positive values refers the opposite. The zero value of CI shows absence of inequality. ${ }^{36}$

$$
c=\frac{2}{\mu} \operatorname{cov}_{w}\left(y_{i}, R_{i}\right)
$$

where $y_{i}$ and $R_{i}$ are the poor IADL or presence of chronic diseases of the $i^{\text {th }}$ individual and the fractional rank of $i^{\text {th }}$ individual of the index of household economic status for weighted data; $\mu$ is the (weighted) mean of both health outcomes of the sample and $\operatorname{cov}_{w}$ denotes the weighted covariance.

Study used method developed by Wagstaff $e t a l^{38}$ to decompose socioeconomic inequality in poor IADL or presence of chronic diseases into its determinants. The method enables to show how factors contribute proportionally to health inequality. For instance, any linear regression model link the outcome of interest, $y$, to a set of $k$ determinants, $X_{k}$ as:

$$
y_{i}=\alpha+\sum_{k=1} \beta_{k} x_{k_{i}}+\epsilon_{i}
$$

where $\epsilon$ is an error term. Given the relationship between $y_{i}$ and $X_{k_{i}}$ in equation (2), the CI for y (C) can be written as:

$$
C=\sum_{k=1}\left(\frac{\beta_{k} \bar{x}_{k}}{\mu}\right) C_{k}+\frac{G C_{\epsilon}}{\mu}=C_{\hat{y}}+\frac{G C_{\epsilon}}{\mu}
$$

where $\mu$ is the mean of $\mathrm{y}, \bar{X}_{k}$ is the mean of $X_{k}, C_{k}$ is the CI for $X_{k}$ (defined analogously to $\mathrm{C}$ ) and, in the last term, $\mathrm{GC}_{\varepsilon}$ is the generalised concentration index for $\epsilon_{i}$.

In equation (3), $\mathrm{C}$ can be thought of as being made up of two components-'explained' and 'unexplained' components. The 'explained' or 'deterministic' component is similar to weighted sum of the CIs of the regressors where the weights are simply the elasticities associated with a percentage change in the explanatory variable $\left(\frac{\beta_{k} \bar{x}_{k}}{\mu}\right)$ of $y$ with respect to each $X_{k}$. On the other hand, 'unexplained' or 'residual' refers to inequality in outcome that cannot be described by systematic variation in the $X_{k}$ across different socioeconomic groups.

To do a decomposition analysis, the following steps are required:

1. The outcome variable against its factors needs to be regress to find out the coefficients of the explanatory variables $\left(\beta_{k}\right)$.

2. Calculate mean of the outcomes and each of its factors $\left(\mu\right.$ and $X_{k}$ ).

3. Using equation (1) where $y_{\mathrm{i}}$ and $\mu$ are determinant for the $\mathrm{i}^{\text {th }}$ individual and the determinant mean, respectively. The values of all variables included in equation (3) are known.

4. At last, the net contribution of each factor can be quantified in two following steps: 
a. Computing net contribution of each factor by multiplying the health outcomes elasticity with respect to that factor and its CI $\left(\frac{\beta_{k} \bar{x}_{k}}{\mu}\right) C_{k}$

b. Calculate the percentage contribution of each factor through dividing its net contribution by the CI of the health outcome $\frac{\left(\frac{\beta_{k} \bar{x}_{k}}{\mu}\right) C_{k}}{C}$.

\section{Ethics statement}

This study used the WHO-SAGE Wave 1 data available in the public domain for use by researchers (http://www. who.int/healthinfo/sage/en/); thus, no ethical clearance is required for this study. The WHO-SAGE survey participants in all selected countries were informed about the survey, design, purpose and how it would benefit society at large. The survey was conducted under the supervision of the respective national governments.

\section{Patient and public involvement}

This study did not involve any patient and/or public.

\section{RESULTS}

Table 1 presents the sample distribution of population aged 60 and above covered in the SAGE survey. Nearly, three-fifths of the sample size belonged to the age group 60-69 years among both men and women. Over half of the women (54\%) were widowed as compared with just $11 \%$ among men. Every three out of four women in the sample did not attend any formal level of schooling, whereas the corresponding figure among men was $36 \%$. Majority of the older population resides in rural areas $(70 \%)$. Nearly $75 \%$ of the men used tobacco, while among women, it was $38 \%$.

The decomposition analysis has been interpreted based on three components: mean, marginal effects and CIs. Negative CI for IADL (or functional deficiencies) indicates that inequality was concentrated among the poor, and positive CI for chronic diseases among the rich, which indicates a higher burden. Positive (negative) contributions of association can be interpreted by indicating that the total health inequality would be lower (higher) if that association had no impact on the health outcome (instead of that reflected in marginal effects). The contributions are a mixture of positives and negatives, which sum up to 100 . The positive percentages were adjusted on a pro rata basis to offset the negative percentages, as the positive percentages exaggerate the importance of the determinants. Each health outcome analysis was trailed by a gender-based comparison to comprehend if there were any real contrasts among the contributions of various sociodemographic constituents among men and women in their income health inequality.

Results of the relative contribution of sociodemographic factors to functional deficiencies were highest among those with poor economic status (39\%), followed by those who were illiterate (23\%), which collated to $61 \%$ of total explained inequalities (table 2). Findings show that nine selected covariates together explained $82 \%$ of the total inequalities. Sex-stratified analysis highlights major contrasts, where the positive adjusted percentile contribution by poor economic status for men was $61.8 \%$, whereas it was negative for women and thus, adjusted on the pro rata basis for other positive contribution factors (table 3). The highest percentile contribution in functional deficiencies among women was rural resident $(50 \%)$, which was substantially low at $5 \%$ among men. The second point of comparison was illiteracy, which was $27 \%$ for men and only $0.1 \%$ for women. Among women, Muslims accounted for $17 \%$ of the total inequality in functional deficiency and SC/ST social groups, another $16 \%$.

In case of chronic health condition (table 4), about $93 \%$ of the relative contribution of sociodemographic factors was shared by three factors-poor economic status $(42 \%)$, rural residence $(31 \%)$ and illiteracy $(20 \%)$. Sex-wise comparison (table 5) suggests that among both men and women, poor economic status (45\% and $41 \%)$ contributed the highest, followed by rural place of residence $(31 \%$ and $27 \%)$ and illiteracy (18\% and $22 \%)$, respectively. However, among women, the contribution of social groups (SCs/STs) was noticeable $(9 \%)$.

\section{DISCUSSION AND CONCLUSION}

Although health disparities by socioeconomic group have been firmly established with years of research, difference in functional ability and chronic health by sex remains inconclusive among older adults in low/middle-income countries. We believe that this is the first study on sex-stratified decomposing socioeconomic inequality in functional deficiency and chronic illness among older adults in India.

The findings show pro-poor inequality in IADL (or functional) deficiency and pro-rich inequality in the presence of chronic illness among older adults sample. Determinants such as poor economic status, illiteracy and rural residence were major contributors to overall IADL deficiency, and there is a similar pattern among men. However, in the case of women, rural residence, belonging to SCs/STs social groups and being Muslim contributed significantly to IADL deficiency. The findings further suggest that poor economic status, followed by rural residence and illiteracy contributed the highest in explaining overall inequality in chronic health. Available evidence from India and other low/ middle income countries highlighted low economic status, ${ }^{27} 39$ poor education ${ }^{40}$ and residential segregation, ${ }^{42-44}$ as key predictors of functional ability and presence of chronic health among older adults. But, hardly any study ever attempted to quantify the contribution of these factors.

Place of residence contributed to about $50 \%$ of the inequality in functional deficiency, and nearly $30 \%$ in case of chronic illness among women. This could perhaps be attributed to excess engagement of women in informal rural activities throughout their life as compared with 
Table 1 Sample distribution for population aged 60 and above, WHO Study on Global AGEing and Adult Health, India

\begin{tabular}{|c|c|c|c|c|c|c|}
\hline \multirow[b]{2}{*}{ Background characteristics } & \multicolumn{2}{|l|}{ Men } & \multicolumn{2}{|c|}{ Women } & \multicolumn{2}{|l|}{ Total } \\
\hline & $\mathbf{n}$ & $\%$ & $\mathbf{n}$ & $\%$ & $\mathbf{n}$ & $\%$ \\
\hline \multicolumn{7}{|l|}{ Age of the respondent } \\
\hline $60-64$ & 615 & 30.0 & 613 & 33.8 & 1228 & 31.9 \\
\hline $65-69$ & 589 & 29.3 & 500 & 25.8 & 1089 & 27.5 \\
\hline $70-74$ & 395 & 21.2 & 335 & 20.1 & 730 & 20.6 \\
\hline $75-79$ & 206 & 11.8 & 153 & 9 & 359 & 10.4 \\
\hline $80+$ & 174 & 7.6 & 173 & 11.1 & 347 & 9.4 \\
\hline \multicolumn{7}{|l|}{ Marital status } \\
\hline Unmarried & 32 & 1.5 & 9 & 1.2 & 36 & 1.4 \\
\hline Married & 1660 & 87.8 & 812 & 44.7 & 2477 & 66.1 \\
\hline Widowed & 287 & 10.5 & 953 & 54 & 1240 & 32.5 \\
\hline \multicolumn{7}{|l|}{ Education of the respondent } \\
\hline No formal education & 745 & 36.3 & 1320 & 75.6 & 2149 & 56.2 \\
\hline Less than primary & 317 & 12.9 & 159 & 9.6 & 446 & 11.2 \\
\hline Completed primary & 341 & 19.5 & 161 & 8.9 & 494 & 14.2 \\
\hline Completed secondary & 234 & 13.0 & 59 & 2.4 & 275 & 7.6 \\
\hline Completed high school & 203 & 11.8 & 52 & 2.2 & 234 & 6.9 \\
\hline Completed college/university/postgraduate & 139 & 6.3 & 23 & 1.1 & 155 & 3.7 \\
\hline \multicolumn{7}{|l|}{ Religion of the respondent } \\
\hline Hinduism & 1603 & 83.7 & 1473 & 86.9 & 3076 & 85.3 \\
\hline Islam & 245 & 12.6 & 170 & 10.3 & 415 & 11.5 \\
\hline Others & 63 & 3.6 & 60 & 2.7 & 123 & 3.2 \\
\hline \multicolumn{7}{|l|}{ Ethnicity of the respondent } \\
\hline Scheduled tribe & 114 & 5.4 & 73 & 4.5 & 187 & 5.0 \\
\hline Scheduled caste & 329 & 16.8 & 284 & 16.8 & 613 & 16.8 \\
\hline No caste or tribe & 340 & 12.9 & 325 & 14.8 & 665 & 13.9 \\
\hline Others & 1122 & 64.8 & 1013 & 63.9 & 2135 & 64.3 \\
\hline \multicolumn{7}{|l|}{ Place of residence } \\
\hline Urban & 472 & 29.6 & 501 & 30.4 & 973 & 30.1 \\
\hline Rural & 1507 & 70.3 & 1273 & 69.5 & 2780 & 69.9 \\
\hline \multicolumn{7}{|l|}{ Wealth quintile } \\
\hline Poorest & 387 & 22.5 & 363 & 24.8 & 750 & 23.7 \\
\hline Poor & 403 & 22.6 & 344 & 21.9 & 747 & 22.3 \\
\hline Middle & 358 & 17.5 & 346 & 19.4 & 704 & 18.5 \\
\hline Higher & 382 & 17.5 & 309 & 15.9 & 691 & 16.8 \\
\hline Highest & 381 & 19.7 & 341 & 17.7 & 722 & 18.8 \\
\hline \multicolumn{7}{|l|}{ Tobacco use } \\
\hline No & 523 & 24.7 & 1110 & 62.3 & 1633 & 43.5 \\
\hline Former/Current & 1387 & 75.2 & 592 & 37.6 & 1979 & 56.5 \\
\hline Total & 1979 & & 1774 & & 3753 & \\
\hline
\end{tabular}

urban women. For instance, in rural areas, women contribute significantly as agricultural labourers and are involved in core household management tasks including livestock rearing, collection of firewood and fetching water even in later life. ${ }^{45}$ Their healthcare needs and nutritional requirements during childhood and adulthood have largely been neglected, in addition to lack of economic security, mobility and poor social interactions within the community. ${ }^{46}$ The high contribution of rural areas in both IADL and chronic illness could be due to 
Open access

Table 2 Contribution of predictor variables based on decomposition analysis for IADL among older population aged 60 years and above, WHO-SAGE 2007-2008

\begin{tabular}{lllllrr}
\hline Covariates & Mean & Beta & Cl & Contribution to Cl & \% Contribution & $\begin{array}{c}\text { Adjusted \% } \\
\text { contribution }\end{array}$ \\
\hline Poor & 0.41 & $0.107 \dagger$ & -0.58 & -0.03 & 38.65 & 38.52 \\
Tobacco use & 0.55 & 0.040 & -0.06 & 0.00 & 2.14 & 2.13 \\
Illiterate & 0.68 & $0.165^{\star *}$ & -0.13 & -0.02 & 22.56 & 22.48 \\
SC/ST & 0.22 & 0.050 & -0.25 & 0.00 & 4.35 & 4.33 \\
Muslim & 0.12 & $0.279^{* \star}$ & -0.13 & -0.01 & 6.09 & 6.07 \\
Rural & 0.74 & $0.156^{\star *}$ & -0.11 & -0.02 & 18.91 & 18.85 \\
Married & 0.65 & $-0.223^{\star *}$ & 0.03 & -0.01 & 6.36 & 6.34 \\
Older (70+) & 0.38 & $0.474^{\star *}$ & 0.00 & 0.00 & -0.34 & 1.28 \\
Female & 0.47 & $0.172^{* *}$ & -0.01 & 0.00 & 1.28 & 100.0 \\
\hline IADL & 0.76 & & -0.11 & -0.09 & 100.0 & \\
\hline
\end{tabular}

Significant levels: ${ }^{* *}<0.01 ; \dagger<0.10$.

IADL, Instrumental Activity of Daily Living; SAGE, Study on Global AGEing and Adult Health.

inadequate healthcare infrastructure, poor accessibility and substandard quality of care. ${ }^{47} 48$ This situation put women at a disproportionate disadvantage compared with their urban counterparts with better civic infrastructure, improved health facilities and regular check-ups.
Thus, the combined effect of heavy physical activities and widespread gender neglect in health and nutrition put rural women at a higher risk of functional limitations during later life as compared with their urban counterparts.

Table 3 Sex-stratified contribution of predictor variables based on decomposition analysis for IADL among older population aged 60 years and above, WHO-SAGE 2007-2008

\begin{tabular}{|c|c|c|c|c|c|c|}
\hline Covariates & Mean & Beta & $\mathbf{C l}$ & Contribution to $\mathrm{Cl}$ & $\%$ Contribution & $\begin{array}{l}\text { Adjusted \% } \\
\text { contribution }\end{array}$ \\
\hline \multicolumn{7}{|l|}{ Male } \\
\hline Poor & 0.41 & $0.252^{\star \star}$ & -0.58 & -0.10 & 62.90 & 61.83 \\
\hline Tobacco use & 0.73 & 0.000 & -0.06 & 0.00 & 0.00 & \\
\hline Illiterate & 0.54 & $0.233^{\star \star}$ & -0.21 & -0.04 & 26.98 & 26.52 \\
\hline SC/ST & 0.23 & -0.030 & -0.24 & 0.00 & -1.73 & \\
\hline Muslim & 0.13 & 0.120 & -0.11 & 0.00 & 1.61 & 1.59 \\
\hline Rural & 0.76 & 0.060 & -0.11 & -0.01 & 5.18 & 5.09 \\
\hline Married & 0.84 & $-0.200^{\star \star}$ & 0.01 & 0.00 & 2.28 & 2.25 \\
\hline Older $(70+)$ & 0.39 & $0.402^{* *}$ & -0.02 & 0.00 & 2.77 & 2.73 \\
\hline IADL & 0.6 & & -0.2 & -0.2 & 100.0 & 100.0 \\
\hline \multicolumn{7}{|l|}{ Female } \\
\hline Poor & 0.42 & -0.060 & -0.58 & 0.02 & -45.38 & \\
\hline Tobacco use & 0.35 & 0.070 & -0.09 & 0.00 & 7.60 & 4.74 \\
\hline Illiterate & 0.84 & 0.000 & -0.08 & 0.00 & 0.23 & 0.14 \\
\hline SC/ST & 0.21 & $0.145 \dagger$ & -0.26 & -0.01 & 26.32 & 16.43 \\
\hline Muslim & 0.10 & $0.509^{\star \star}$ & -0.16 & -0.01 & 27.12 & 16.93 \\
\hline Rural & 0.72 & $0.290^{* *}$ & -0.12 & -0.03 & 79.52 & 49.64 \\
\hline Married & 0.45 & $-0.244^{\star \star}$ & 0.05 & -0.01 & 19.42 & 12.12 \\
\hline Older (70+) & 0.37 & $0.551^{* *}$ & 0.02 & 0.01 & -14.81 & \\
\hline IADL & 0.90 & & -0.04 & -0.03 & 100.0 & 100.0 \\
\hline
\end{tabular}

Significant levels: ${ }^{* *}<0.01 ; \dagger<0.10$.

IADL, Instrumental Activity of Daily Living; SAGE, Study on Global AGEing and Adult Health. 
Table 4 Contribution of predictor variables based on decomposition analysis for chronic disease of all the older population aged 60 years and above, WHO-SAGE 2007-2008

\begin{tabular}{lllllcc}
\hline Covariates & Mean & Beta & Cl & Contribution to Cl \% Contribution & $\begin{array}{c}\text { Adjusted \% } \\
\text { contribution }\end{array}$ \\
\hline Poor & 0.41 & $-0.113^{* *}$ & -0.58 & 0.06 & 42.60 & 42.25 \\
\hline Tobacco & 0.55 & 0.020 & -0.06 & 0.00 & -0.84 & \\
Illiterate & 0.68 & $-0.143^{\star *}$ & -0.13 & 0.03 & 20.47 & 20.30 \\
SC/ST & 0.22 & $-0.071^{*}$ & -0.25 & 0.01 & 6.13 & 6.07 \\
Muslim & 0.12 & -0.030 & -0.13 & 0.00 & 0.65 & 0.65 \\
Rural & 0.74 & $-0.242^{\star *}$ & -0.11 & 0.05 & 30.73 & 30.48 \\
Married & 0.65 & 0.010 & 0.03 & 0.00 & 0.15 & 0.15 \\
Older (70+) & 0.38 & $0.091^{\star *}$ & 0.00 & 0.00 & 0.07 & 0.07 \\
Female & 0.47 & 0.000 & -0.01 & 0.00 & 0.03 & 0.03 \\
Chronic Disease & 0.43 & & 0.15 & 0.15 & 100.0 & 100.0 \\
\hline
\end{tabular}

Significant levels: ${ }^{*}<0.05 ;{ }^{* *}<0.01$.

SAGE, Study on Global AGEing and Adult Health.

The combined influence of social group (SCs/STs) and religion (Muslim) contributes to over $30 \%$ of the inequality in IADL disability among women. There were similar observations by other Indian studies among older population, where particular social groups were more disadvantaged in health and healthcare. ${ }^{49}$ Complex interactions exist between social groups (castes) and religion in India where substantial inequality is present by gender, access to education, economic status and social groups. ${ }^{50}$ The SC/ST and Muslim population, particularly women, are disadvantaged socioeconomically compared with other social groups. Historically, they are socially

Table 5 Sex-stratified contribution of predictor variables based on decomposition analysis for chronic disease of all the older population aged 60 years and above, WHO-SAGE 2007-2008

\begin{tabular}{|c|c|c|c|c|c|c|}
\hline Covariates & Mean & Beta & $\mathrm{Cl}$ & Contribution to $\mathrm{Cl}$ & $\%$ Contribution & $\begin{array}{l}\text { Adjusted \% } \\
\text { contribution }\end{array}$ \\
\hline \multicolumn{7}{|l|}{ Male } \\
\hline Poor & 0.41 & $-0.119^{\star \star}$ & -0.58 & 0.06 & 45.75 & 45.04 \\
\hline Tobacco & 0.73 & -0.010 & -0.06 & 0.00 & 0.36 & 0.35 \\
\hline Illiterate & 0.54 & $-0.104^{\star \star}$ & -0.21 & 0.03 & 18.59 & 18.30 \\
\hline $\mathrm{SC} / \mathrm{ST}$ & 0.23 & -0.030 & -0.24 & 0.00 & 3.05 & 3.00 \\
\hline Muslim & 0.13 & -0.070 & -0.11 & 0.00 & 1.61 & 1.59 \\
\hline Rural & 0.76 & $-0.247^{\star *}$ & -0.11 & 0.04 & 31.78 & 31.28 \\
\hline Married & 0.84 & 0.030 & 0.01 & 0.00 & 0.45 & 0.45 \\
\hline Older (70+) & 0.39 & $0.149^{\star \star}$ & -0.02 & 0.00 & -1.59 & \\
\hline Chronic Disease & 0.45 & & 0.14 & 0.14 & 100.0 & 100.0 \\
\hline \multicolumn{7}{|l|}{ Female } \\
\hline Poor & 0.42 & $-0.115^{\star \star}$ & -0.58 & 0.07 & 42.60 & 41.15 \\
\hline Tobacco & 0.35 & 0.040 & -0.09 & 0.00 & -1.80 & \\
\hline Illiterate & 0.15 & $-0.226^{\star \star}$ & -0.08 & 0.04 & 23.32 & 22.53 \\
\hline SC/ST & 0.21 & $-0.110^{*}$ & -0.26 & 0.02 & 9.27 & 8.95 \\
\hline Muslim & 0.10 & 0.030 & -0.16 & 0.00 & -0.84 & \\
\hline Rural & 0.72 & $-0.221^{\star \star}$ & -0.12 & 0.05 & 28.09 & 27.14 \\
\hline Married & 0.45 & -0.020 & 0.05 & 0.00 & -0.88 & \\
\hline Older (70+) & 0.37 & 0.020 & 0.02 & 0.00 & 0.24 & 0.24 \\
\hline Chronic Disease & 0.41 & & 0.16 & 0.16 & 100.0 & 100.0 \\
\hline
\end{tabular}

Significant levels: ${ }^{*}<0.05 ;{ }^{* *}<0.01$. 
excluded, illiterate and mainly engage in the informal sectors or as agricultural labourers. ${ }^{50}$ Thus, there is the likelihood of reporting physical deficiency among women belonging to these social and religious groups. However, more research is required to establish this fact, at least in the case of Muslim women. Although, in recent years many affirmative initiatives have been launched to ensure better education, occupation and livelihood opportunities to those belonging to SCs/STs, especially women, it is too early to expect any major change.

Economic status was found to be the major contributor in explaining inequality in both IADL and chronic illness among older adults. However, sex-stratified analysis suggests that household economic status was a major factor in both IADL and chronic illness among men. But, in the case of women, household economic status and not IADL deficiency contributed to chronic illness. Earlier evidence supports these results and states that lack of economic support to older adults increased the likelihood of underutilisation of healthcare services in case of any morbidity/illness. ${ }^{43}$ Studies argue that when it comes to interaction between gender and wealth, Indian women are at a disadvantage due to the long history of patriarchal kinship and economic structure at the household level. ${ }^{51-53}$ Studies have documented that women in South Asia have restricted access to, and control over, resources within the household ${ }^{50}$ poor access to preventive and curative care as they are economically dependent on their husbands or on the male heads of household ${ }^{54}$ and are most vulnerable when healthcare has to be purchased out-of-pocket or through private insurance ${ }^{55-57}$ Resourcepoor older individuals had lower use of healthcare despite their illness and this could be affecting women adversely considering the inadequate social protection plan, coupled with poor performance, specifically for the economically disadvantaged older people. ${ }^{58}$ This was reflected in earlier studies, too.

\section{Strengths and limitations}

The strengths and limitations of the study need to be highlighted. The methodological strength of the present study includes application of the concentration index. It is sensitive to changes in the outcome distribution (IADL and chronic illness) of the population across socioeconomic groups. The application of decomposition analysis ${ }^{38}$ to examine the contribution of socioeconomic factors to the overall health inequality between the poor and the rich strengthens the findings of this study. Another major strength of this study is the nationally representative sample of older population drawn from the SAGE survey. SAGE is one of the prominent sources of data that provides substantial health and related information pertaining to the older population in India. It has addressed major data gaps in terms of growing socioeconomic inequalities in health in low/middle-income countries like India. ${ }^{14}$ The study has used diagnosed chronic morbidity rather than reported to reduce any bias in the responses.
As far as the limitations are concerned, first, the findings based on regression-based decomposition models lack any causal interpretations. Second, the study does not include any variables related to psychosocial factors and the health system, which might explain both functional limitations and chronic illness among older adults. Third, the cross-sectional study design prevents establishment of any causal inferences from the study results. Finally, how health measures could have been affected by the type and composition of an individual's social network ${ }^{33}$ has not been considered in this analysis.

Contributors PKS contributed in conceptualising the study. LS and RG had full access to the data and take responsibility for the integrity of the data and the accuracy of data analysis. RKR and PKS contributed to the interpretation of the data. PKS and LS critically revised all the versions of the manuscript. LS, RG, RKR and PKS approved the final version of the manuscript.

Funding The authors have not declared a specific grant for this research from any funding agency in the public, commercial or not-for-profit sectors.

Competing interests None declared.

Patient consent for publication Not required.

Provenance and peer review Not commissioned; externally peer reviewed.

Data sharing statement The WHO SAGE data can be downloaded from the link: https://www.who.int/healthinfo/sage/e.

Open access This is an open access article distributed in accordance with the Creative Commons Attribution Non Commercial (CC BY-NC 4.0) license, which permits others to distribute, remix, adapt, build upon this work non-commercially, and license their derivative works on different terms, provided the original work is properly cited, appropriate credit is given, any changes made indicated, and the use is non-commercial. See: http://creativecommons.org/licenses/by-nc/4.0/.

\section{REFERENCES}

1. Wray LA, Blaum CS. Explaining the role of sex on disability: a population-based study. Gerontologist 2001;41:499-510.

2. Barford A, Dorling D, Smith GD, et al. Life expectancy: women now on top everywhere: during 2006, even in the poorest countries, women can expect to outlive men. BMJ Br Med J 2006;332:808.

3. Oksuzyan A, Juel K, Vaupel JW, et al. Men: good health and high mortality. Sex differences in health and aging. Aging Clin Exp Res 2008;20:91-102.

4. Crimmins EM, Kim JK, Solé-Auró A. Gender differences in health: results from SHARE, ELSA and HRS. Eur J Public Health 2011;21:81-91.

5. Yount KM, Agree EM. Differences in disability among older women and men in Egypt and Tunisia. Demography 2005;42:169-87.

6. $\mathrm{Ng} \mathrm{N}$, Kowal P, Kahn K, et al. Health inequalities among older men and women in Africa and Asia: evidence from eight Health and Demographic Surveillance System sites in the INDEPTH WHO-SAGE study. Glob Health Action 2010;3:5420.

7. Deighton CM, Surtees D, Walker DJ. Influence of the severity of rheumatoid arthritis on sex differences in health assessment questionnaire scores. Ann Rheum Dis 1992;51:473-5.

8. Kandrack MA, Grant KR, Segall A. Gender differences in health related behaviour: some unanswered questions. Soc Sci Med 1991;32:579-90.

9. Goli S, Singh L, Jain K, et al. Socioeconomic determinants of health inequalities among the older population in India: a decomposition analysis. J Cross Cult Gerontol 2014;29:353-69.

10. Rajan SI. Social assistance for poor elderly: How effective? Econ Polit Wkly 2001:613-7.

11. Legato MJ, Johnson PA, Manson JE. Consideration of sex differences in medicine to improve health care and patient outcomes. JAMA 2016;316:1865-6.

12. MOHFW. National Health Policy 2017. 2017 https://mohfw.gov.in/ sites/default/files/9147562941489753121.pdf.

13. Patel V, Chatterji S, Chisholm D, et al. Chronic diseases and injuries in India. Lancet 2011;377:413-28.

14. Kowal P, Chatterji S, Naidoo N, et al. Data resource profile: the World Health Organization Study on global AGEing and adult health (SAGE). Int J Epidemiol 2012;41:1639-49. 
15. Arokiasamy P, Parasuraman S, Sekher T V, et al. Study on global AGEing and adult health (SAGE) Wave 1, India National Report. Int Inst Popul Sci Geneva World Heal Organ 2013.

16. Pérès $\mathrm{K}$, Helmer $\mathrm{C}$, Letenneur $\mathrm{L}$, et al. Ten-year change in disability prevalence and related factors in two generations of French elderly community dwellers: data from the PAQUID study. Aging Clin Exp Res 2005;17:229-35.

17. Barberger-Gateau P, Rainville $C$, Letenneur L, et al. A hierarchical model of domains of disablement in the elderly: a longitudinal approach. Disabil Rehabil 2000;22:308-17.

18. Fujiwara $\mathrm{Y}$, Shinkai $\mathrm{S}$, Kumagai $\mathrm{S}$, et al. Longitudinal changes in higher-level functional capacity of an older population living in a Japanese urban community. Arch Gerontol Geriatr 2003;36:141-53.

19. Díaz-Venegas C, Reistetter TA, Wang CY, et al. The progression of disability among older adults in Mexico. Disabil Rehabil 2016;38:2016-27.

20. Sengupta M, Agree EM. Gender and disability among older adults in north and South India: differences associated with coresidence and marriage. J Cross Cult Gerontol 2002;17:313-36.

21. Chen M, Drèze J. Widows and health in rural north India. Econ Polit Wkly 1992:WS81-92.

22. Krochalk PC, Li Y, Chi I. Widowhood and self-rated health among Chinese elders: the effect of economic condition. Australas J Ageing 2008;27:26-32.

23. Manzoli L, Villari P, M Pirone G, et al. Marital status and mortality in the elderly: a systematic review and meta-analysis. Soc Sci Med 2007;64:77-94.

24. Drèze J, Srinivasan PV. Widowhood and poverty in rural India: Some inferences from household survey data. J Dev Econ 1997;54:217-34.

25. Herd P, Goesling B, House JS. Socioeconomic position and health: the differential effects of education versus income on the onset versus progression of health problems. J Health Soc Behav 2007;48:223-38.

26. Elo IT. Social class differentials in health and mortality: patterns and explanations in comparative perspective. Annu Rev Sociol 2009;35:553-72.

27. Roy K, Chaudhuri A. Influence of socioeconomic status, wealth and financial empowerment on gender differences in health and healthcare utilization in later life: evidence from India. Soc Sci Med 2008;66:1951-62.

28. Das Gupta M, Zhenghua J, Bohua L, et al. Why is Son preference so persistent in East and South Asia? a cross-country study of China, India and the Republic of Korea. J Dev Stud 2003;40:153-87.

29. Mini GK, Thankappan KR. Pattern, correlates and implications of non-communicable disease multimorbidity among older adults in selected Indian states: a cross-sectional study. BMJ Open 2017;7:e013529.

30. Cramm JM, Lee J. Smoking, physical activity and healthy aging in India. BMC Public Health 2014:14:526.

31. Bhan N, Srivastava S, Agrawal S, et al. Are socioeconomic disparities in tobacco consumption increasing in India? A repeated crosssectional multilevel analysis. BMJ Open 2012;2:e001348.

32. Corsi DJ, Subramanian SV, Lear SA, et al. Tobacco use, smoking quit rates, and socioeconomic patterning among men and women: a cross-sectional survey in rural Andhra Pradesh, India. Eur J Prev Cardiol 2014;21:1308-18.

33. Singh L, Singh PK, Arokiasamy P. Social network and mental health among older adults in Rural Uttar Pradesh, India: a cross-sectional study. J Cross Cult Gerontol 2016;31:173-92.

34. Ferguson BD, Tandon A, Gakidou E, et al. Estimating permanent income using indicator variables. Heal Syst Perform Assess debates, methods empiricism Geneva World Heal Organ 2003:747-60.
35. Hosseinpoor AR, Van Doorslaer E, Speybroeck N, et al. Decomposing socioeconomic inequality in infant mortality in Iran. Int J Epidemiol 2006;35:1211-9.

36. Wagstaff $A$, Paci $P$, van Doorslaer E. On the measurement of inequalities in health. Soc Sci Med 1991;33:545-57.

37. van Doorslaer E, Koolman X. Explaining the differences in incomerelated health inequalities across European countries. Health Econ 2004;13:609-28.

38. Wagstaff A, van Doorslaer E, Watanabe N. On decomposing the causes of health sector inequalities with an application to malnutrition inequalities in Vietnam. J Econom 2003;112:207-23.

39. Vellakkal S, Subramanian SV, Millett C, et al. Socioeconomic inequalities in non-communicable diseases prevalence in India: disparities between self-reported diagnoses and standardized measures. PLoS One 2013;8:e68219.

40. Duda RB, Anarfi JK, Adanu RM, et al. The health of the "older women" in Accra, Ghana: results of the Women's Health Study of Accra. J Cross Cult Gerontol 2011;26:299-314.

41. Zhang H, Bago d'Uva T, van Doorslaer E. The gender health gap in China: a decomposition analysis. Econ Hum Biol 2015;18:13-26.

42. Basu S, King AC. Disability and chronic disease among older adults in India: detecting vulnerable populations through the WHO SAGE Study. Am J Epidemiol 2013;178:1620-8.

43. Dhak B. Gender difference in health and its determinants in the oldaged population in India. J Biosoc Sci 2009;41:625-43.

44. Zeki Al Hazzouri A, Mehio Sibai A, Chaaya M, et al. Gender differences in physical disability among older adults in underprivileged communities in Lebanon. J Aging Health 2011;23:367-82.

45. Singh L, Arokiasamy P, Singh PK, et al. Determinants of gender differences in self-rated health among older population. Sage Open 2013;3:21.

46. Ghosh S, Husain Z. Economic independence, family support and perceived health status of the elderly: Recent evidence from India. Asia Pac Popul J 2011;25:47-77.

47. Agarwal A, Lubet A, Mitgang E, et al. Population aging in india: facts, issues, and options. 2016

48. Zhou B, Chen K, Wang J, et al. Quality of life and related factors in the older Rural and Urban Chinese populations in zhejiang province. $J$ App/ Gerontol 2011;30:199-225.

49. Brinda EM, Attermann J, Gerdtham UG, et al. Socio-economic inequalities in health and health service use among older adults in India: results from the WHO Study on Global AGEing and adult health survey. Public Health 2016;141:32-41.

50. Iyer A, Sen G, Ostlin P. The intersections of gender and class in health status and health care. Glob Public Health 2008;3 Suppl $1: 13-24$.

51. Kuhn R, Caldwell JC. Routes to low mortality in poor countries revisited. Popul Dev Rev 2010;36:171-220.

52. Das GM. Life course perspectives on women's autonomy and health outcomes. Am Anthropol 1995;97:481-91.

53. Santow G. Social roles and physical health: the case of female disadvantage in poor countries. Soc Sci Med 1995;40:147-61.

54. Schuler SR, Bates LM, Islam MK. Paying for reproductive health services in Bangladesh: intersections between cost, quality and culture. Health Policy Plan 2002;17:273-80.

55. Sen G, Östlin P. Gender inequity in health: why it exists and how we can change it. Glob Public Health 2008;3:1-12.

56. Ravindran STK, de PH. The right reforms? Health sector reforms and sexual and reproductive health, 2005.

57. Falkingham J. Poverty, out-of-pocket payments and access to health care: evidence from Tajikistan. Soc Sci Med 2004;58:247-58.

58. Balarajan Y, Selvaraj S, Subramanian SV. Health care and equity in India. Lancet 2011;377:505-15. 